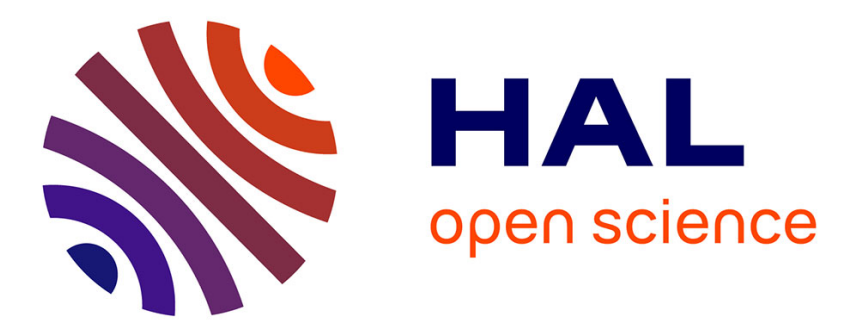

\title{
Combining geostatistics and physically-based flow-and-transport simulations to characterize contaminated soils
}

Mathieu Le Coz, Léa Pannecoucke, Xavier Freulon, Charlotte Cazala, Chantal de Fouquet

\section{To cite this version:}

Mathieu Le Coz, Léa Pannecoucke, Xavier Freulon, Charlotte Cazala, Chantal de Fouquet. Combining geostatistics and physically-based flow-and-transport simulations to characterize contaminated soils. EGU General Assembly 2020, EGU 2020, Jun 2020, VIENNE, Austria. 10.5194/egusphere-egu20205486 . hal-02929850

\section{HAL Id: hal-02929850 https://hal.science/hal-02929850}

Submitted on 6 Jan 2021

HAL is a multi-disciplinary open access archive for the deposit and dissemination of scientific research documents, whether they are published or not. The documents may come from teaching and research institutions in France or abroad, or from public or private research centers.
L'archive ouverte pluridisciplinaire HAL, est destinée au dépôt et à la diffusion de documents scientifiques de niveau recherche, publiés ou non, émanant des établissements d'enseignement et de recherche français ou étrangers, des laboratoires publics ou privés.

$$
\text { Copyright }
$$




\title{
Combining geostatistics and physically-based flow-and-transport simulations to characterize contaminated soils
}

\author{
Mathieu Le Coz*, Léa Pannecoucke**, Xavier Freulon**, Charlotte Cazala*, Chantal de \\ Fouquet** \\ *Institute for Radiological protection and Nuclear Safety (IRSN), PSE-ENV/SEDRE, 31 \\ avenue de la Division Leclerc, 92260 Fontenay-aux-Roses, France \\ **MINES ParisTech, PSL University, Centre de Géosciences, 35 rue Saint-Honoré, 77300 \\ Fontainebleau, France
}

\begin{abstract}
:
Characterization of contamination in soils resulting from nuclear activities is a crucial issue for site remediation. A classical approach consists in delineating the contaminated zones based on a geostatistical estimation calibrated from measured activities, but it results in high uncertainties when the number of measurements is low and/or the spatial variability of the studied variable is governed by complex processes. In order to reduce these uncertainties, a novel approach, called Kriging with Numerical Variogram (KNV), is developed: the variogram is computed from a set of physically-based flow-and-transport simulations rather than from the measurements.
\end{abstract}

The KNV approach is assessed on a two-dimensional synthetic reference test case reproducing the migration of a tritium plume within an unsaturated soil with hydraulic properties highly variable in space. In this case, the KNV method reduces the mean absolute error by $50 \%$ to $75 \%$ compared to classical geostatistical approaches, depending on the sampling scenario. The performance of KNV regarding the classification into contaminated or not-contaminated zones is yet sensitive to the contamination threshold.

The KNV approach could thus help to better estimate volumes of soils to be decontaminated in the context of remediation of nuclear sites. This approach can be transposed to other scales of heterogeneities, such as systems with several geological units, or other pollutants with a more complex chemical behaviour, as soon as a numerical code that simulates the phenomenon under study is available.

\section{INTRODUCTION}

Kriging is used to map contamination in soils and groundwater by providing estimates of pollutant concentration at unsampled locations (e.g., [1] and [2]). However, the quality of the kriging estimator strongly depends on the ability to model the spatial structure of the studied variable through the variogram or the covariance function. In particular, the kriging estimator is often poorly accurate if the number of sampled values is low or if the spatial variability of the studied variable is governed by complex processes ([3] and [4]).

Physically-based numerical simulations of flow and solute transport are another widely used approach to assess contaminated soils and groundwater (e.g., [5] and [6]). Such simulations take into account complex processes governing contamination spread but they require a relevant definition of initial and boundary conditions, as well as internal hydraulic properties. Within the unsaturated zone, the inference of these hydraulic properties is difficult, timeconsuming and the induced uncertainties result in a lack of accuracy in the characterization of the contaminated areas ([7]). 
The present study aims at combining kriging and flow-and-transport simulations, by computing the mean of experimental variograms from outputs of numerical simulation (hence they are called numerical variograms), in order to improve the characterization of a contaminant plume under a complex configuration, i.e., by considering transient unsaturated flow and highly variable hydraulic properties.

\section{KRIGING WITH NUMERICAL VARIOGRAM (KNV)}

Ordinary kriging is widely used to map pollutant concentrations in soil and groundwater. The estimate of the variable of interest $Z$ at a target point $x_{0}, Z^{*}\left(x_{0}\right)$, is a linear combination of the observations:

$$
Z^{*}\left(x_{0}\right)=\sum_{a=1}^{N} \lambda_{a} Z\left(x_{a}\right)
$$

where $\lambda_{a}$ are the kriging weights to be determined and $x_{a}$ are the locations of the $N$ observations. Ordinary kriging assumes that (i) the mean of the regionalized variable $(Z)$ under study is constant but unknown; and (ii) the variance of any increments, i.e. the variogram function is known for any pairs of points in the studied domain ([8]).

Instead of computing the variogram from observations, numerical variograms are computed from several realizations of $Z$. These realizations result from a physically-based model, e.g., flow and transport simulations of a contaminant plume for the application presented in this study. The numerical variogram $\gamma$ between two points $x$ and $x^{\prime}$ is the average of the increments computed on the $P$ realizations:

$$
\gamma\left(x, x^{\prime}\right)=\frac{1}{P} \sum_{p=1}^{P} \frac{1}{2}\left[Z_{p}(x)-Z_{p}\left(x^{\prime}\right)\right]^{2}
$$

where $Z_{p}(x)$ (resp. $\left.Z_{p}\left(x^{\prime}\right)\right)$ is the value of $Z$ at location $x$ (resp. $x$ ) for the $\mathrm{p}$-th simulation.

\section{METHOD}

In order to assess the KNV approach, a synthetic reference test case is considered. This reference case consists in a two-dimensional vertical domain of $100 \mathrm{~m}$ large by $15 \mathrm{~m}$ deep in an unsaturated zone contaminated with a point source of tritiated water, and it is built as follows:

- A triplet of random fields describing the proportions of sand, silt and clay (i.e., soil textural properties) are generated by considering (i) a normal distribution of these proportions; and (ii) a spatial variability implemented through an exponential variogram with anisotropy between the horizontal and vertical directions.

- The textural properties are converted into Mualem-van Genuchten hydraulic parameters, governing unsaturated flow ([9] and [10]), by means of the rosetta3 pedo-transfer function ([11]).

- The hydraulic parameter fields are used as inputs to MELODIE flow-and-transport numerical code ([12]) for simulating the evolution of the tritium plume during five years.

Both the soil texture and the tritium activity are sampled in seven boreholes crossing the reference case (Fig. 1). The KNV approach is then carried out to estimate the tritium activity within the whole domain from these punctual sampling:

-The sampled soil textures are used to compute experimental variograms, which allow the generation of 2,000 triplets of conditional fields of sand, silt and clay contents.

- The textural property fields are converted into hydraulic parameter fields by means of rosetta3 pedo-transfer function. 
- The hydraulic parameter fields are used as inputs to the flow-and-transport code to simulate 2,000 tritium plumes (all the other model parameters are kept constant compared to the reference test case).

- The set of 2,000 simulated plumes is used to compute the numerical variograms between each couple of points needed to build the kriging system.

The KNV estimates are compared to the activities of the reference test case and two other kriging methods are used as benchmarks, ordinary kriging (OK, [8]) and kriging with an external drift (KED, [13]).

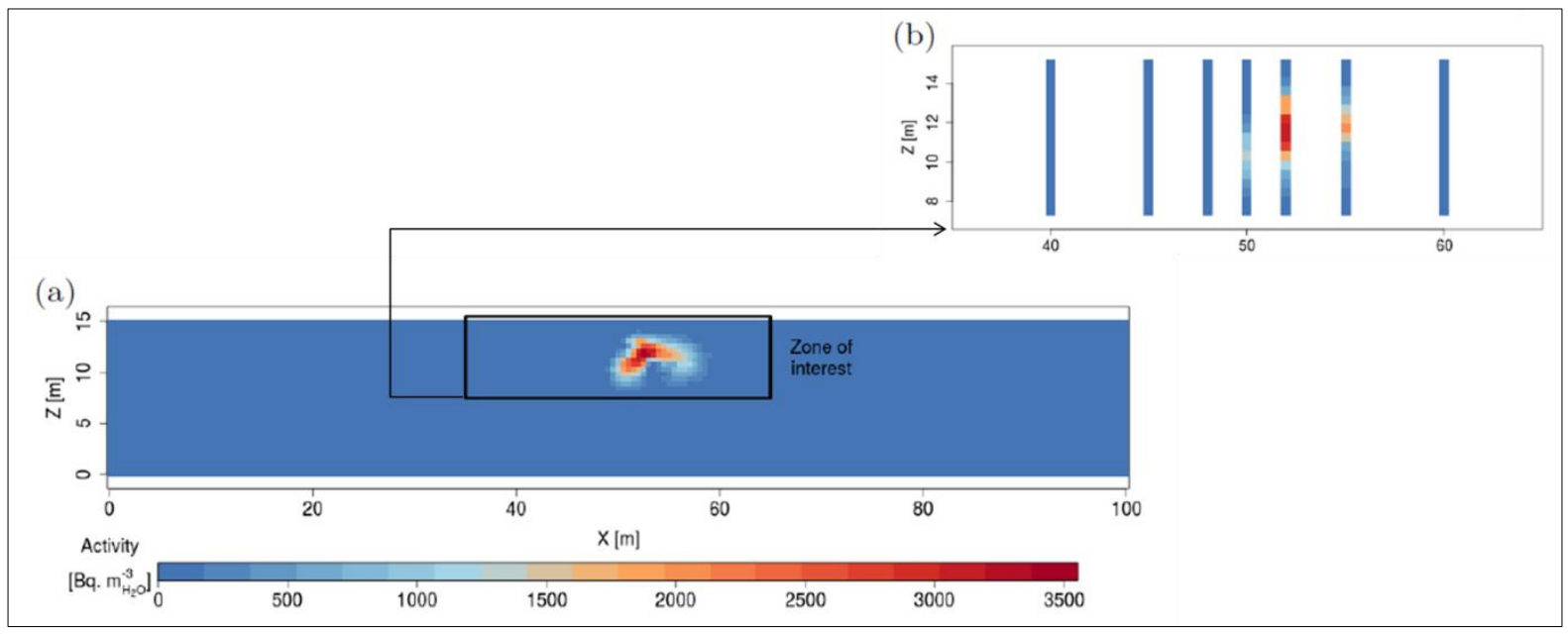

Fig. 1. Reference test case: simulated tritium plume (a); and activities sampled for assessing the KNV approach (b).

\section{$4 \quad$ RESULTS}

The maps of estimation are almost similar for the three methods (Fig. 2). Yet, the errors are higher for OK (Root Mean Square Error, RMSE $=161$ Bq. $\mathrm{m}^{-3} \mathrm{H}_{2} \mathrm{O}$ ) and KED (RMSE $=138$ Bq. $\left.\mathrm{m}^{-3} \mathrm{H}_{2} \mathrm{O}\right)$ than for KNV (RMSE $\left.=89 \mathrm{~Bq} \cdot \mathrm{m}^{-3} \mathrm{H}_{2} \mathrm{O}\right)$.

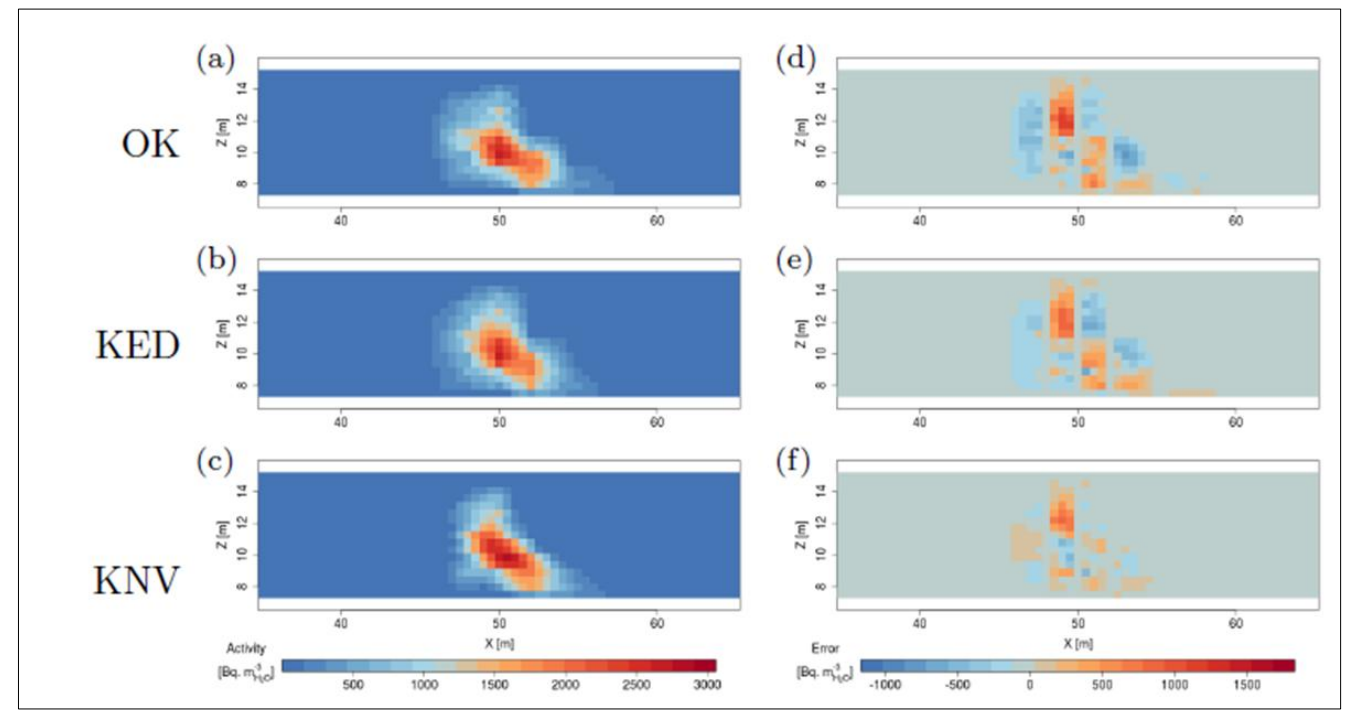

Fig. 2. Map of estimation obtained with the OK (a), KED (b) and KNV (c) approaches; and maps of corresponding estimation errors (d, e and f).

The proportion of false-positive (i.e., contaminated on the estimation, not contaminated on the reference) surface is smaller for KNV that for OK, whatever the contamination threshold (Fig. 3a). This proportion is reduced of $10 \%$, except for contamination thresholds above $1,000 \mathrm{~Bq} \cdot \mathrm{m}^{-3} \mathrm{H}_{2} \mathrm{O}$. The proportion of false-positive surface is smaller for KED than for KNV for 
very low contamination thresholds (below 20 Bq. ${ }^{-3} \mathrm{H}_{2} \mathrm{O}$ ); for higher contamination thresholds, KNV leads to smaller proportion of false-positive surfaces than KED.

The proportion of false-negative (i.e., contaminated on the reference, not contaminated on the estimation) surface is slightly higher for KNV than for OK and KED for contamination thresholds below 500 Bq. ${ }^{-3} \mathrm{H}_{2} \mathrm{O}$ (Fig. 3b). For higher contamination thresholds, KNV performs better than OK and KED.

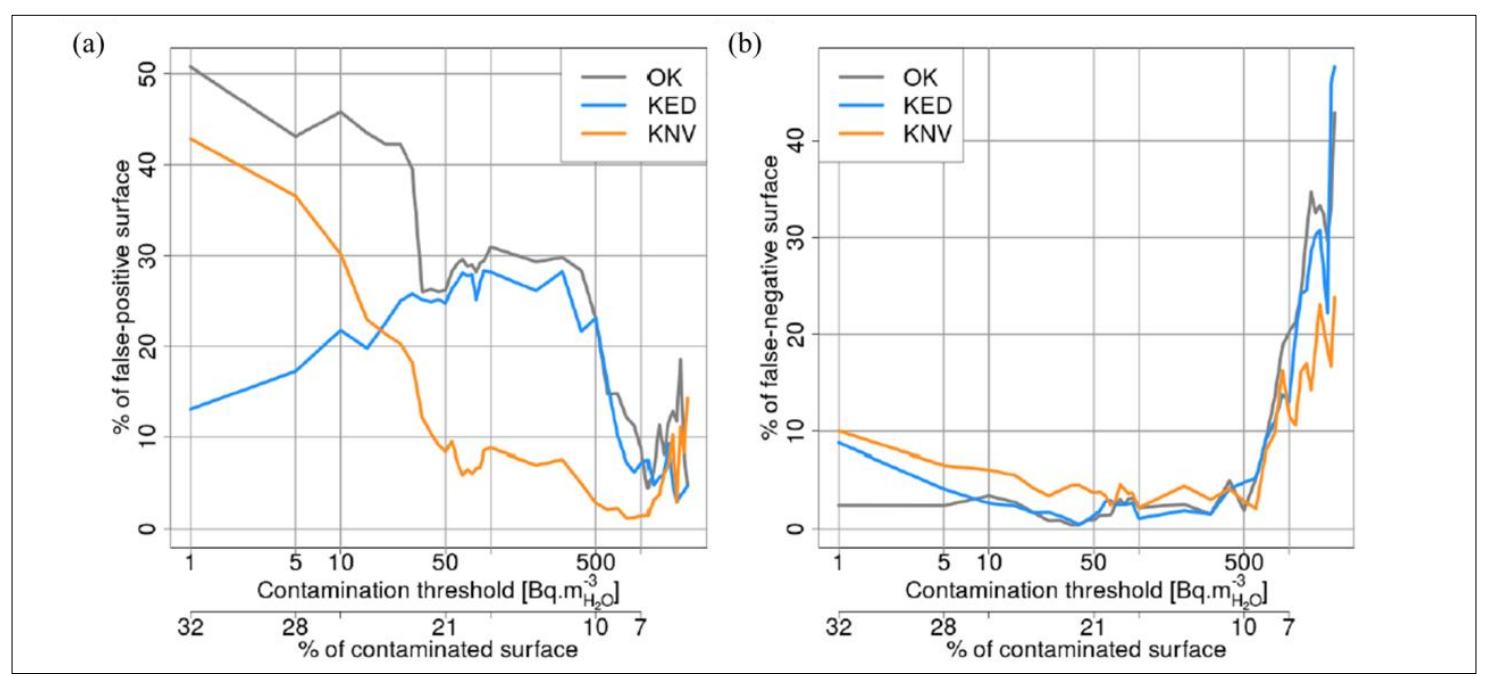

Fig. 3. Proportion of false-positive (a) and false-negative (b) surfaces in function of the contaminated threshold.

\section{CONCLUSION}

The KNV approach, consisting in using flow-and-transport simulation outputs to compute numerical variograms, appears to perform better than standard geostatistical tools to improve plume characterization. Additional tests show that KNV appears to be particularly interesting when the available observations are scarce (when reference test case activity is sampled in four boreholes, OK RMSE is $348 \mathrm{~Bq} \cdot \mathrm{m}^{-3} \mathrm{H}_{2} \mathrm{O}$; KED RMSE is $174 \mathrm{~Bq} \cdot \mathrm{m}^{-3} \mathrm{H}_{2} \mathrm{O}$; and KNV RMSE is $\left.147 \mathrm{~Bq} \cdot \mathrm{m}^{-3} \mathrm{H}_{2} \mathrm{O}\right)$.

The assessment procedure detailed in this study is based on a synthetic case study with boundary conditions supposed to be exactly known. The next step will be to carry out the method on an actual contaminated site.

This work is part of the Kri-Terres project, supported by the French National Radioactive Waste Management Agency (Andra) under the "Investments for the Future" Program.

More details about this work are given in a research article submitted for publication in a scientific peer-review journal ([14]).

\section{References}

[1] Pelillo, V., Piper, L., Lay-Ekuakille, A., Lanzolla, A., Andria, G., Morello, R., 2014. Geostatistical approach for validating contaminated soil measurements. Measurement 47, 1016-1023.

[2] Liang, C.-P., Chen, J.-S., Chien, Y.-C., Chen, C.-F., 2018. Spatial analysis of the risk to human health from exposure to arsenic contaminated groundwater: A kriging approach. Science of The Total Environment 627, 1048-1057.

[3] Webster, R., Oliver, M. A. Geostatistics for Environmental Scientists, 2nd Edition. Statistics in Practice. Wiley edition, 2007. 
[4] Wang, Y., Akeju, O. V., Zhao, T., 2017. Interpolation of spatially varying but sparsely measured geo-data: A comparative study. Engineering Geology 231, 200-217.

[5] Bugai, D., Skalskyy, A., Dzhepo, S., Kubko, Y., Kashparov, V., Van Meir, N., Stammose, D., Simonucci, C., Martin-Garin, A., 2012. Radionuclide migration at experimental polygon at Red Forest waste site in Chernobyl zone. Part 2: Hydrogeological characterization and groundwater transport modeling. Applied Geochemistry 27 (7), 1359-1374.

[6] Testoni, R., Levizzari, R., De Salve, M., 2017. Coupling of unsaturated zone and saturated zone in radionuclide transport simulations. Progress in Nuclear Energy 95, 84-95.

[7] Pannecoucke, L., Le Coz, M., Houze, C. Saintenoy, A., Cazala, C., de Fouquet, C., 2019. Impact of spatial variability in hydraulic parameters on plume migration within unsaturated surficial formations. Journal of Hydrology 574, 160-168.

[8] Chiles, J.-P., Delfiner, P. Geostatistics: Modeling Spatial Uncertainty, 2nd Edition. Wiley series in probability and statistics. Wiley edition, 2012.

[9] Mualem, Y., 1976. A new model for predicting the hydraulic conductivity of unsaturated porous media. Water Resources Research 12 (3), 513-522.

[10] van Genuchten, M. T., 1980. A closed-form equation for predicting the hydraulic conductivity of unsaturated soils. Soil Science Society of America Journal 44 (5), 892-898.

[11] Zhang, Y., Schaap, M. G., 2017. Weighted recalibration of the Rosetta pedotransfer model with improved estimates of hydraulic parameter distributions and summary statistics (Rosetta3). Journal of Hydrology 547, 39-53.

[12] IRSN, 2009. MELODIE Modèle d'Evaluation à LOng terme des Déchets Irradiants Enterrés. Notice théorique du code de calcul MELO version 5.0. (in french).

[13] Rivest, M., Marcotte, D., Pasquier, P., 2008. Hydraulic head field estimation using kriging with an external drift: A way to consider conceptual model information Journal of Hydrology 361 (3), 349-361.

[14] Pannecoucke, L., Le Coz, M., Freulon, X., de Fouquet, C., 2019. Combining geostatistics and simulations of flow and transport to characterize contamination within the unsaturated zone. Science. of the Total Environment, under review. 